\title{
Using Two-component Epoxy Resin for Asphalt Pavement Applications-Part A: Curing Behaviors
}

\author{
Fan $\mathrm{He}^{1, \mathrm{a}}$, Fusong Wang ${ }^{2, \mathrm{~b}}$, Chao $\mathrm{Li}^{3, \mathrm{c}}$, Yue Xiao ${ }^{4, \mathrm{~d}}$ \\ ${ }^{1}$ School of Materials Science and Engineering, Wuhan University of Technology, \\ Wuhan, 430070, China \\ ${ }^{2}$ State Key Laboratory of Silicate Materials for Architectures, Wuhan University of Technology, \\ Wuhan, 430070, China \\ ${ }^{3}$ State Key Laboratory of Silicate Materials for Architectures, Wuhan University of Technology, \\ Wuhan, 430070, China \\ ${ }^{4}$ State Key Laboratory of Silicate Materials for Architectures, Wuhan University of Technology, \\ Wuhan, 430070, China \\ aemail: 18707255819@sina.cn, bemail: 18202772328@163.com, \\ 'email: Lic@whut.edu.cn, demail: xiaoy@whut.edu.cn
}

Keywords: Epoxy resin, Curing behavior, Direct tensile strength, Asphalt pavement.

\begin{abstract}
The curing behaviors of two-component epoxy resin was studied by means of Direct Tensile Test (DTT) in this research at the curing condition of $14{ }^{\circ} \mathrm{C}$. The direct tensile strength was investigated as well. Research results illustrates that the investigated two-component epoxy resin needs about 4 days to get fully cured. While it has a DTS of $5 \mathrm{MPa}$ after less than 1 day curing. The tensile strength of fully cured epoxy resin is dependent on the test temperature. The direct tensile strength of fully cured epoxy resin can reach to $20 \mathrm{MPa}$. The failure strain of epoxy resin is very small and not sensitive to the temperature and displacement rate.
\end{abstract}

\section{Introduction}

The binder properties have a significant contribution to the field performance of asphalt pavement. Traditionally, bituminous binders were used. But with respect to the increasing traffic loads, bituminous binders need to be improved. SBS modified bitumen shows good cohesion, low temperature susceptibility, excellent elasticity [1]. SBR, rubber powder, EVA were reported as excent modifier to improve the performance of bituminous materials [2].

However, modified bituminous binders may not be good enough for special applications, such as antiskid surfaces at traffic-lights, gas stations and airfield runways. Raveling or loss of aggregates from the pavement surface is the main failure mechanism with bitumen based mixtures used for these applications [3]. Epoxy resin has excellent adhesion and raveling resistance. It has been successfully and widely used for durable road markings and bridge deck surfaces [4, 5]. These applications indicate that epoxy resin may be an excellent option to be used for surfaces on road pavements. In order to understand the possibility of using epoxy resin for pavement applications, tests on two-component epoxy resin were therefore conducted. This paper presents the research results.

\section{Materials and Methodologies}

The two-component epoxy resin was obtained from Latexfalt Company in the Netherlands. Component $\mathrm{A}$ is epoxy based binder, while component $\mathrm{B}$ is the hardening component. The specimens of two-component epoxy resin were prepared as: 1 , add component $\mathrm{B}$ to component $\mathrm{A} ; 2$, then this mixture is thoroughly mixed until a homogeneous mixture is obtained (1-2 minutes). Thorough homogeneous mixing of components $\mathrm{A}$ and $\mathrm{B}$ is needed to get the optimal characteristics of binders; 3. after mixing component $\mathrm{A}$ and $\mathrm{B}$ together, the mixture of epoxy resin is poured into the DTT silicon rubber mould (see Fig. 1). Air voids need to be carefully avoided in this process. 
When pouring the liquid binder into the mould, over filling is needed to ensure that enough binder is available to completely fill the mould. After over filling, a flat silicon rubber was then carefully placed on top of the mould to make a flat surface. After the preparation process, samples were cured at $14{ }^{\circ} \mathrm{C}$. DTTs were then conducted at different curing time to characterize the curing property of epoxy resin.

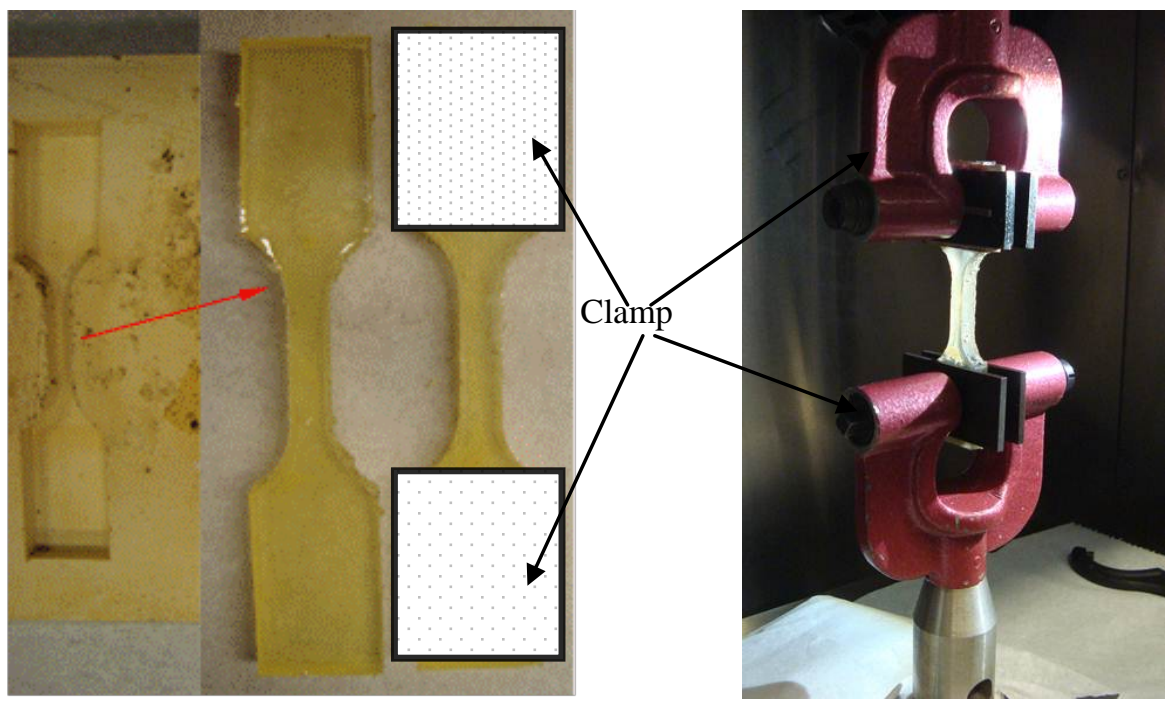

Fig. 1 Typical Specimens and DTT test setup

The DTT was employed to investigate the curing behavior, tensile strength and failure strain. The specimens were tested at a constant tensile displacement rate until they failed. The applied force and resulting displacement were recorded during the test. The stress at the failure point is so called Direct Tensile Strength (DTS, MPa). The following equations were used to calculate the DTS and strain.

$$
\begin{aligned}
& \text { Failure stress: } & \text { DTS } & =\frac{P_{f}}{A} \\
& \text { Failure Strain: } & \varepsilon & =\frac{D}{L_{e}}
\end{aligned}
$$

Where, A is the original cross-sectional area, $\left[\mathrm{mm}^{2}\right]$, here A $=36 \mathrm{~mm}^{2} ; P_{f}$ is the failure load, [N]. $\varepsilon$ is the failure strain; D is the displacement at failure, [mm]; $L_{e}$ is the effective length of the DTT specimens, [mm].

Dumbbell shape specimens as shown in Fig. 1 were used in this research. Two clamps were introduced to eliminate the influence of interface failure. The contact surfaces on the clamps are rough enough to prevent from slipping between specimen and clamps.

Fig. 2 shows the typical test results obtained with a dumbbell shape specimen during a DTT test. When a constant displacement rate is applied, the responding force sharply increases at the beginning. Before the specimen fails, there is a more or less certain force plateau which is the failure propagation stage. The shorter the failure propagation stage is, the more brittle the material is. When the applied displacement reaches the maximum strain, the specimen fails immediately. The failure propagation of epoxy resin is just few seconds. The displacement elongation is very limited and therefore resulted tensile strain is very small. 


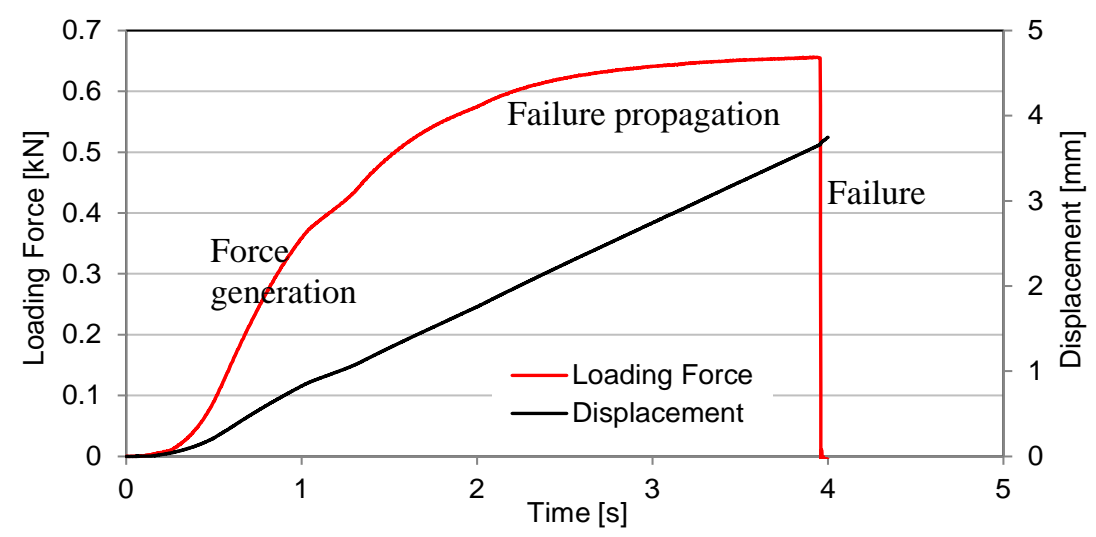

Fig. 2 Typical displacement and loading curves from DTT

\section{Research Results Analysis}

Curing Behavior. The curing behavior is a critical factor which will influence the application of using the binder for pavement surfaces. The faster the curing speed is, the more economical the surfacing application is. Especially when the binder is used on busy areas, it should cure fast enough to reopen to the traffic in a short time. Therefore, it is necessary to investigate the curing behavior.

Specimens were kept in a storage room at $14{ }^{\circ} \mathrm{C}$ and $70 \%$ relative humidity after sample preparation. DTTs were conducted after different curing times. Tests were done at $10{ }^{\circ} \mathrm{C}$ with a displacement rate of $1 \mathrm{~mm} / \mathrm{min}$. Maximum force and displacement at failure were recorded. Fig. 3 conclues the influences of curing time on the tensile strength and failure strain. The curing curves were fitted by means of a sigmoidal curve [4].

After short curing times, the epoxy resin has only a lower tensile strength and a larger failure strain. The tensile strength is increasing until it reaches its maximum after being fully cured. Obviously, the tested two-component epoxy resin needs about 4 days to get fully cured. However, it has a DTS of 5 MPa after less than 1 day curing, which is higher than the DTS value of traditional bituminous binders. In practice, the contact of epoxy resin with aggregate and environmental factors as wind and higher ambient temperature will accelerate the curing speed. The fully cured epoxy resin has very low failure strain, which is smaller than $10 \%$.

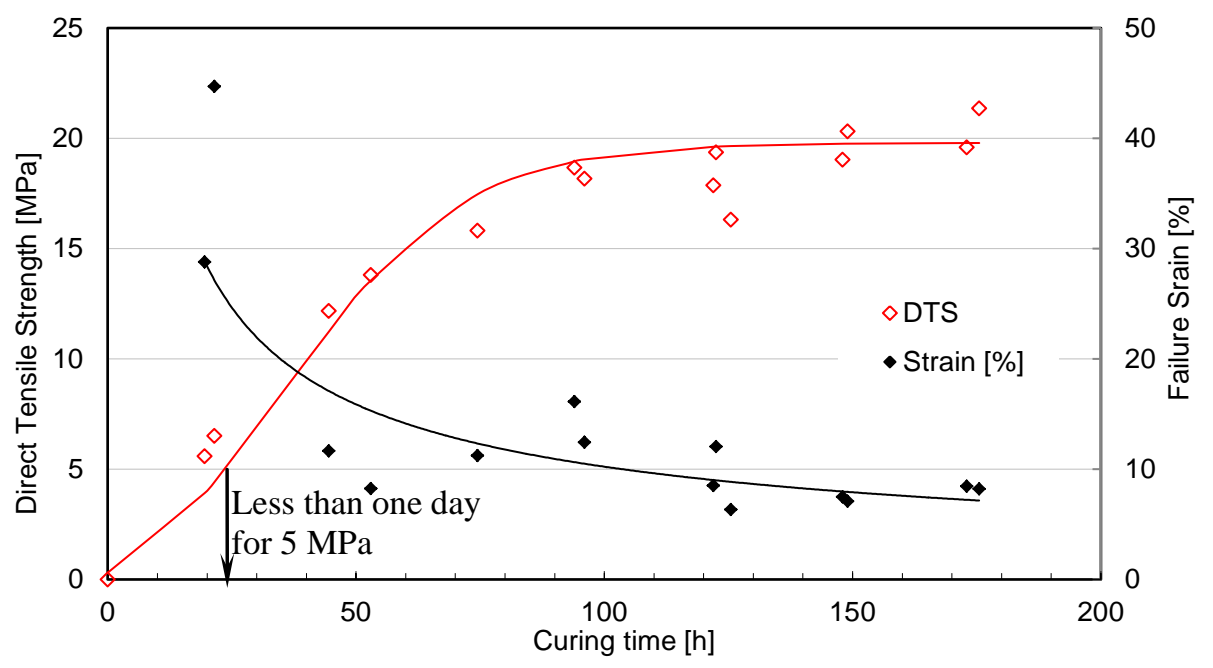

Fig. 3 Effect of curing time on the DTS and failure strain of epoxy resin

Direct Tensile Strength. DTT tests were carried out on fully cured specimens at temperatures of $0{ }^{\circ} \mathrm{C}, 10{ }^{\circ} \mathrm{C}$ and $20{ }^{\circ} \mathrm{C}$. The applied displacement rate was $1 \mathrm{~mm} / \mathrm{min}$. The influence of the displacement rate on the tensile strength was investigated at $10^{\circ} \mathrm{C}$ using displacement rates of 1 
$\mathrm{mm} / \mathrm{min}$ and $10 \mathrm{~mm} / \mathrm{min}$. Fig. 4 shows the displacement-applied force curves from DTT tests. At lower temperature as $0{ }^{\circ} \mathrm{C}$, the failure propagation stage can be observed.

Table 1 presents the DTS and failure strain at different temperatures and displacement rates. The data shows that the DTS of epoxy resin is dependent on the test temperature. The tensile strength is higher at $0{ }^{\circ} \mathrm{C}$ than the tensile strength at $10^{\circ} \mathrm{C}$ and $20^{\circ} \mathrm{C}$. But the difference in tensile strength between $10^{\circ} \mathrm{C}$ and $20^{\circ} \mathrm{C}$ is not significant. The applied displacement rate does not seem to have a significant effect on the tensile strength.

The failure strain is in the range of $7.2 \%$ to $11.5 \%$ and is not very sensitive to the test temperature and displacement speed. Basically, a viscoelastic material will behave more brittle at faster loading rates, which means that the strain at failure would decrease with increasing loading rate. But the results shown in Table 1 do not fit this theory. The influence of loading rate on the failure strain cannot be determined.

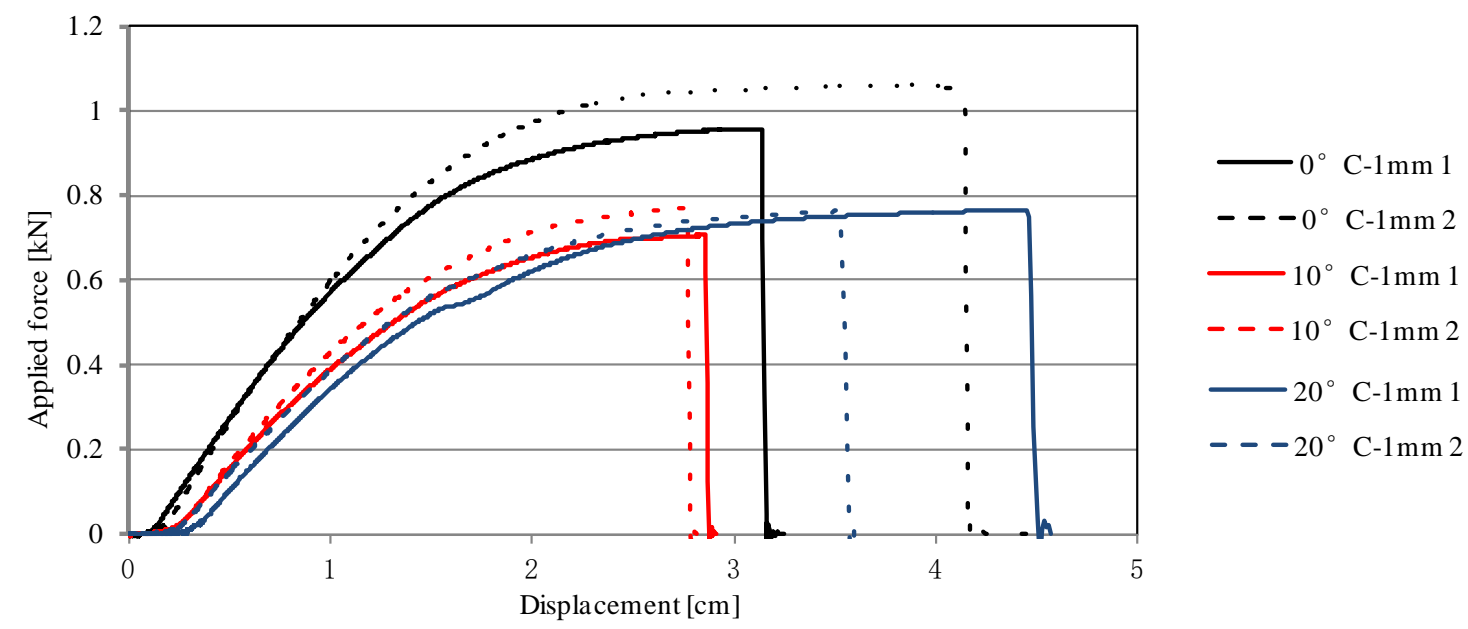

Fig. 4 Displacement-Force curves from DTT

Table 1 DTT test results on MER

\begin{tabular}{|c|c|c|c|c|c|c|c|c|}
\hline & \multicolumn{4}{|c|}{ Failure Strength [MPa] } & \multicolumn{4}{c|}{ Failure Strain [\%] } \\
\hline Disp. speed & \multicolumn{3}{|c|}{$1 \mathrm{~mm} / \mathrm{min}$} & $10 \mathrm{~mm} / \mathrm{min}$ & \multicolumn{3}{c|}{$1 \mathrm{~mm} / \mathrm{min}$} & $10 \mathrm{~mm} / \mathrm{min}$ \\
\hline Temperature & $0{ }^{\circ} \mathrm{C}$ & $10{ }^{\circ} \mathrm{C}$ & $20^{\circ} \mathrm{C}$ & $10^{\circ} \mathrm{C}$ & $0{ }^{\circ} \mathrm{C}$ & $10^{\circ} \mathrm{C}$ & $20^{\circ} \mathrm{C}$ & $10^{\circ} \mathrm{C}$ \\
\hline Specimen 1 & 26.56 & 19.58 & 18.39 & 21.17 & 9.26 & 8.46 & 11.48 & 13.08 \\
\hline Specimen 2 & 29.47 & 21.36 & 18.61 & 21.11 & 11.54 & 8.2 & 7.22 & 10.44 \\
\hline Average & 28.01 & 20.47 & 18.5 & 21.14 & 10.4 & 8.33 & 9.35 & 1.76 \\
\hline
\end{tabular}

\section{Summary}

Based on the research results obtained from the Direct Tensile Test on two-component epoxy resin, the following items can be concluded:

1. The tested two-component epoxy resin needs about 4 days to get fully cured. However, it has a DTS of $5 \mathrm{MPa}$ after less than 1 day curing, which is higher than the DTS value of traditional bituminous binders.

2. The tensile strength of epoxy resin is dependent on the test temperature. The direct tensile strength of fully cured epoxy resin can reach to $20 \mathrm{MPa}$. The applied displacement rate does not have a significant effect. The failure strain of epoxy resin is very small and not sensitive to the temperature and displacement rate.

\section{Acknowledgement}

The project was supported by the International Science \& Technology Cooperation Program of China (No. 2013DFE83100), the Open Fund of the Key Laboratory of Highway Engineering in 
Special Regions of Ministry of Education of China, Chang'an University (No. 310821161105), the Open Fund of the Key Laboratory of Road Structure and Material of Ministry of Transport (Changsha University of Science \& Technology, No. kfj150302) and the Scientific Research Foundation for Returned Overseas Chinese Scholars, State Education Ministry.

\section{References}

[1] P.Q. Cui, S.P. Wu, F.Z. Li, Y. Xiao, and H.H. Zhang, Investigation on Using Sbs and Active Carbon Filler to Reduce the Voc Emission from Bituminous Materials, Mater. 7 (2014), 6130-43.

[2] L.T. Mo, M. Huurman, S.P. Wu, and A.A.A. Molenaar, Ravelling Investigation of Porous Asphalt Concrete Based on Fatigue Characteristics of Bitumen-Stone Adhesion and Mortar, Mater. Design, 30 (2009), 170-79.

[3] Y. Xiao, M. F. C. van de Ven, A. A. A. Molenaar, Z. Su, and K. Chang, Design Approach for Epoxy Modified Bitumen to Be Used in Antiskid Surfaces on Asphalt Pavement, Constr. Build. Mater. 41 (2013), 516-25.

[4] Y. Xiao, M. van de Ven, A. Molenaar, Z. Su, and F. Zandvoort, Characteristics of Two-Component Epoxy Modified Bitumen, Mater. Struct. 44 (2011), 611-22.

[5] Y. Yildirim, Polymer Modified Asphalt Binders, Constr. Build. Mater. 21 (2007), 66-72. 